\title{
Profetismo e Apocalíptica no Zand i Wahman Yasn
}

\author{
Prophetism and Apocalyptic in the Zand i Wahman Yasn
}

\begin{abstract}
Rodrigo Nunes do Nascimento ${ }^{1}$
${ }^{1}$ Graduado e Mestre em História pela Universidade de Brasília (UnB) com orientação do Prof. Dr. Henrique Modanez de Sant'anna. Especialização em Profetismo e Apocalíptica: Perspectivas e Interpretações pela Universidade Metodista de São Paulo. E-mail: rodrigo.nunes90@gmail.com.
\end{abstract}

Recebido em 13 de maio de 2020; Aceito em 11 de outubro de 2020.

DOI: $10.12957 /$ nearco.2020.50951

\section{Resumo}

O artigo apresenta uma análise literária do Zand $\imath$ Wahman Yasn, procurando compreendê-lo em seus próprios termos e com apoio de outras fontes da literatura em persa médio. Pretende-se contextualizar a obra numa comparação cultural e religiosa com experiências análogas em textos proféticos e apocalípticos judaicos. Ao dar ênfase ao profetismo, a abordagem comparativa tenciona suspender o peso das categorias do gênero apocalíptico aplicadas ao Zand $\grave{\imath}$ Wahman Yasn a fim de uma melhor compreensão de sua natureza compósita.

Palavras-chave: Profetismo; Literatura Apocalíptica; Apocalipsismo Persa; Iranologia.

\begin{abstract}
The article presents a literary analysis of the Zand $i$ Wahman Yasn, seeking to understand it on its own terms and with support from other sources of Middle Persian literature. It is intended to contextualize the work on a comparison with similar cultural and religious experiences in Jewish prophetic and apocalyptic texts. By giving enfasis to the prophetism, the comparative approach intends to suspend the weight of the apocalyptic genre categories applied to the Zand $\iota$ Wahman Yasn in order to a better understanding of its composite nature.
\end{abstract}

Keywords: Prophetism; Apocalyptic Literature; Persian Apocalypticism; Iranology.

A produção acadêmica sobre os textos apocalípticos da literatura em persa médio recorre a analogias e termos já utilizados para a apocalíptica judaica. A tipologia clássica desse tipo de literatura entre os judeus divide os textos do gênero em dois 
NEARCD: Revista Eletrônica de Antiguidade 2020, Volume XII, Número II - ISSN IS882-8713

Núcleo de Estudas da Antiguidade - NEA

Universidade do Estado do Rio de Janeiro

ISSN 1982-8713

grandes grupos: apocalipses históricos e apocalipses de jornadas ao além ${ }^{234}$. Dessa divisão nasceram várias categorias de análise para lidar com as estruturas literárias e visão de mundo desse estilo, popularizando-se entre os estudiosos.

É comum considerar o Zand $\imath$ Wahman Yasn, ${ }^{235}$ texto da literatura em persa médio, um apocalipse do tipo "histórico", principalmente devido a sua semelhança com o livro bíblico de Daniel ${ }^{236}$ (DELITZSCH, 1855, p. 271-287, EDDY, 1961, p. 15-36, COLLINS, 1979, p. 14 e 208). No entanto, já se argumentou que suas características com vislumbres do fenômeno visionário, revelação e escatologia revelam um mixtum compositum, ou seja, não é um apocalipse original, mas uma compilação secundária de materiais apocalípticos de diversas origens (HULTGÅRD, 1983, p. 388, 1991, p. 120-121, CERETI, 1995, p. 11).

Considerando uma escala maior, a distinção entre profetismo e apocalíptica é uma realidade quando se trata da literatura bíblica e apócrifa judaica. Como movimentos religiosos que foram registrados na literatura, profetismo e apocalíptica estão presentes também no zoroastrismo, a religião da Pérsia pré-islâmica que é avaliada como uma das mais antigas religiões proféticas (HINTZE, 2012, p. 43).

\footnotetext{
${ }^{234} \mathrm{Em}$ Semeia 14 foi feito um esforço para a construção de uma tipologia do gênero apocalíptico. No

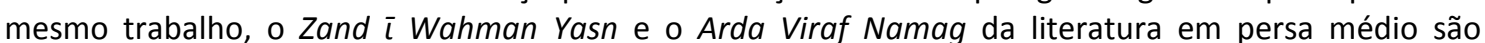
categorizados como, respectivamente, apocalipses do tipo histórico e de jornada ao além (COLLINS, 1979, p. 1-19).

${ }^{235}$ Daqui em diante utilizarei a abreviatura ZWY para designar o Zand $\iota$ Wahman Yasn. A edição crítica da obra, que serviu de base para este artigo, é CERETI, 1995.

${ }^{236}$ Há uma quantidade expressiva de temas e ideias do apocalipticismo judaico cristão que são atestáveis no zoroastrismo, principal tradição religiosa da Pérsia antiga no império Aquemênida (a partir de Dario I) e no período sassânida ( 224 - 652 d.C.). O fim do mundo e suas tribulações, a luta de Deus e seu messias contra o mal, a ressurreição dos mortos e a renovação do mundo são algumas delas (HULTGÅRD, 1998, p. 39). Diante disso, acadêmicos como Boyce e Cohn argumentaram a favor de uma influência persa decisiva como fonte para o desenvolvimento de tais ideias entre os judeus (BOYCE, 1984, p. 57-75; COHN, 1993). Outros nomes importantes no debate que compartilham desta mesma perspectiva são Hultgård, Widengren (1995), Hartmann, Kippenberg (1978) e associados à tradição da Religionsgeschichte Schule (Escola de História das Religiões) principalmente Bousset, Reitzenstein e Otto (GIGNOUX, 1988, p. 67-76).
} 
ISSN 1982-8713

Por ser tradicionalmente categorizado como um texto apocalíptico, análises do ZWY destacam as características estruturais do gênero. Collins argumenta que o ZWY contém todas as características chaves de um apocalipse do tipo histórico. Além da periodização da história, ais escatológicos, ressurreição e forças sobrenaturais do bem e do mal, o texto apresenta uma visão da história numa revelação que é interpretada por um ser divino numa profecia ex eventu, ou seja, após os acontecimentos (COLLINS, 1998, p. 30-32).

É necessário, no entanto, suspender o peso das categorias e reconhecer que o estudo de um texto como o ZWY exige atenção a aspectos que geralmente são deixados de lado, como os traços do profetismo que podem ser encontrados nele e que serão ressaltados neste trabalho. Refletindo sobre a ideia de que gêneros nem sempre definem textos, mas funcionam dentro deles como ferramentas composicionais (SWEENEY, 1996, p. 14), é legítimo o empreendimento de destacar traços e ferramentas que não pertencem apenas ao gênero apocalíptico no ZWY.

A partir de uma análise literária do ZWY, procurando compreendê-lo em seus próprios termos e com apoio de outras fontes da literatura em persa médio, pretendese contextualizá-lo numa comparação cultural e religiosa com experiências análogas em textos proféticos e apocalípticos judaicos. Para isso algumas definições básicas: a de profeta, como aquele que ao participar do transcendente recebe a revelação e a comunica a outros (NEHER, 1975, p. 10); e a de apocalipsismo, como ideias sobre o fim e renovação do mundo dispostas num conjunto da história cósmica, transmitidas num contexto revelatório e geralmente em situações de crise (HULTGÅRD, 1998, p. 40).

Os problemas de datação e contextualização histórica do $Z W Y^{237}$, e da literatura em persa médio no geral, são bem conhecidos pelos iranólogos. Apesar dos manuscritos

237 Esse "Apocalipse zoroástrico" foi preservado na literatura pahlavi, que assim como o Avesta, possui inúmeros problemas de datação. A língua do ZWY é o persa médio, mas em um de seus sistemas de escrita, o pahlavi (o outro é o pazand). O persa médio equivale ao período da língua persa entre 300 a.C. até 950 d.C., e de acordo com Boyce, só no período sassânida (224 - 652 d.C.) é que os textos sagrados 
NEARCD: Revista Eletrônica de Antiguidade 2020, Volume XII, Número II - ISSN IS882-8713

Núcleo de Estudas da Antiguidade - NEA

Universidade do Estado do Rio de Janeiro

ISSN 1982-8713

datarem do período islâmico, é comum o argumento de que o texto possui camadas redacionais do período sassânida com ideias que foram preservadas por tradição oral desde o próprio Zoroastro. ${ }^{238}$ Há ainda a questão da historicidade e contexto histórico do profeta que teria sido o fundador do zoroastrismo. Essas questões não serão discutidas a fundo aqui, pois os objetivos centrais são pensar o papel desempenhado por Zoroastro no ZWY, as possibilidades de profetismo e os elementos do apocalipsismo persa no texto.

\section{Zoroastro como Profeta; Profetismo Iraniano}

No capítulo primeiro e terceiro do ZWY Zoroastro conversa diretamente com Ahura Mazda. ${ }^{239}$ Essa consulta com perguntas e respostas entre o deus e um ser humano tornou-se um tópos, caracterizando mesmo um gênero literário, a literatura ham-pursagīh, presente no Avesta jovem e na literatura em persa médio (HULTGÅRD, 1998, p. 43-44, HINTZE, 2012, p. 44). No caso do ZWY, o padrão do estilo ham-pursagīh se desenvolve entre os capítulos quatro e sete, onde são revelados e descritos a Zoroastro os acontecimentos do fim de seu milênio (CERETI, 1995, p. 9).

\footnotetext{
do zoroastrismo começaram a passagem da tradição oral para a escrita (1968, p. 31-32). Há ainda uma teoria de que o ZWY seria o comentário (zand) do Bahman Yasht, um hino do Avesta (e, portanto, escrito em avéstico) que teria se perdido. Gignoux argumentou contra tal teoria (1986, p. 87-97), pois defende a composição do ZWY no século XI ou X d.C. do período islâmico.

238 No entanto, mesmo entre os iranólogos, há vozes dissonantes no debate. A principal delas é a de Gignoux, que argumenta veemente pelo caráter tardio da apocalíptica persa como um constructo da época sassânida, período já avançado da história iraniana, dentro do molde judaico-cristão (1988, p. 7677). Duchesne-Guillemin, no mesmo sentido, atesta que há certamente uma influência, mas seria o contrário, os iranianos teriam adaptado o modelo do gênero apocalíptico judaico-cristão para suas próprias peculiaridades históricas (1982).

${ }^{239}$ É importante ter em vista que é impossível verificar e assegurar a realidade histórica de quaisquer experiências religiosas descritas nos textos trabalhados neste artigo, sejam elas persas ou judaicas. Principalmente no caso dos textos judaicos, acreditar, que permanece uma questão de fé, foge aos procedimentos metodológicos da ciência histórica. As narrativas das experiências e suas similaridades literárias são o foco do artigo.
} 
ISSN 1982-8713

Nos Gathas, Zoroastro é literariamente investido de autoridade profética e de sacerdote (zaotā). Apesar de ser considerado o fundador da religião mazdeiana e autor dos Gathas, não há evidências suficientes para estabelecer autoria, bem como a existência, terra natal e datação de Zoroastro. De acordo com a tradição zoroástrica, o profeta teria se encontrado com Ahura Mazda aos trinta anos de idade. Nos textos sagrados Zoroastro supostamente refere-se a si mesmo como sacerdote e alguém que possui o conhecimento espiritual, ou seja, ele é o meio pelo qual as verdades e ensinamentos sobre a religião de Ahura Mazda, dēn $\grave{\imath}$ ohrmazd, ${ }^{240}$ são revelados (HUTTER, 2009, HINTZE, 2012, p. 44-47).

Embora seja representado como profeta e sacerdote nos Gathas, não se pode afirmar que o Zoroastro do ZWY cumpre esse mesmo papel sem uma análise mais acurada. Da mesma forma, não quero argumentar que o fato dele ser considerado um profeta faz do ZWY um texto intrinsecamente profético, os argumentos são de outra natureza.

O trecho do ZWY que talvez seja o que mais sugere Zoroastro como profeta encontra-se em 4.67: "Então disse Ahura Mazda ao Spitāmān Zoroastro: 'Estude e memorize o zand e o pāzand, ensine a redenção, conte aos sacerdotes e aos discípulos e eles contarão adiante no mundo". Aqui temos evidência da designação de uma função profética para Zoroastro no texto, como a figura que recebe a revelação e que, principalmente, é responsável pela comunicação a outros.

O ZWY relata que por duas vezes Zoroastro pediu que Ahura Mazda o tornasse imortal, para que os homens melhores cressem na religião por causa de sua imortalidade (1.1, 3.1-5). Dada a impossibilidade de Zoroastro se tornar imortal, pois assim não seria possível a ressurreição dos mortos e o corpo final, o profeta fica

${ }^{240}$ CPD, dēn [dyn'], religião; $\bar{~}[Y]$, de; ohrmazd ['whrmzd], Ahura Mazda. CPD = MACKENZIE, 1971. 
NEARCD: Revista Eletrônica de Antiguidade 2020, Volume XII, Número II - ISSN IS882-8713

Núcleo de Estudas da Antiguidade - NEA

Universidade do Estado do Rio de Janeiro

ISSN 1982-8713

descontente e Ahura Mazda, em sua onisciência, resolve recompensá-lo com o êxtase profético e visões:

Ele pegou a mão de Zarduxšt, ele - Ohrmazd, o espírito generoso, o Criador do mundo dos seres materiais, santo - colocou sua sabedoria de onisciência, em forma de água, na mão de Zarduxšt e disse, "Beba". E Zarduxšt bebeu. Ele colocou a sabedoria de onisciência em Zarduxšt. Sete dias e noites esteve Zarduxšt na sabedoria de Ohrmazd (ZWY 3.6-8). ${ }^{241}$

A partir desse trecho pode-se perceber que a experiência visionária de Zoroastro no ZWY é ligeiramente diferente da experiência do sábio Viraf no Arda Viraf Namag, ${ }^{242}$ embora esta obra também seja categorizada como um apocalipse, mas do tipo "jornada ao além" (COLLINS, 1979, p. 213). Zoroastro tem acesso e contato direto com Ahura Mazda, o que é expresso pelo verbo no plural ham-pursēm (conversamos, ZWY 1.8), enquanto Viraf tem acesso às revelações por meio de um auxiliar, Adur. Além disso, Viraf utilizou um elemento alucinógeno, o mang, para conseguir o êxtase ${ }^{243}$ (AVN 2.9, 15-16), enquanto no ZWY Zoroastro é induzido ao êxtase pela divindade.

No paradigma tradicional da literatura apocalíptica a maneira como a revelação é veiculada envolve a mediação de um ser do além, geralmente um anjo ou Cristo, em alguns textos cristãos (COLLINS, 1979, p. 6). Enquanto a apocalíptica parece dar ênfase nos mediadores de menor grandeza da revelação (anjos), a relação de proximidade entre Zoroastro e Ahura Mazda, o deus criador, lembra muito mais os comissionamentos dos profetas no judaísmo. Tomando o exemplo de Isaías em sua visão e chamamento percebe-se que o profeta viu Yahweh (Is 6.1), e depois de ter os lábios

\footnotetext{
241 /6/ "u-š ān ì zarduxšt dast frāz grift u-š - ohrmazd, mēnōg < i > abzōnīg, dādār ī gēhān < i > astōmandān ì ahlaw - u-š xrad i harwisp-ăgāhīh pad āb kirb abar dast i zarduxšt kard u-š guft kū, frāz xwar. /7/ ud zarduxšt aziš frāz xward. u-š xrad i harwisp-āgāhīh frāz pad zarduxšt andar gumēxt. /8/ haft rōz-šabān zarduxšt andar ohrmazd-xradīh būd".

${ }^{242}$ No entanto, há evidências de jornada ao além também no ZWY, já que Zoroastro tem uma visão das setes regiões do mundo, do céu e do inferno (HULTGÅRD, 1991, p. 129-130). Esses temas, porém, são pouco desenvolvidos na obra.

${ }^{243}$ A experiência de Viraf possui elementos de viagem xamânica, ele alcança um aparente estado de morte por meio do uso de alucinógeno e sua alma, dissociada do corpo, faz uma viagem ao paraíso e ao inferno (AVN 3.1-2, GIGNOUX, 1981, p. 245-247).
} 
NEARCD: Revista Eletrônica de Antiguidade 2020, Volume XII, Número II - ISSN IS82-8713

Núclea de Estudas da Antiguidade - NEA

Universidade do Estado do Rio de Janeiro

ISSN 1982-8713

tocados com uma brasa viva de um dos serafins (6.6-7), ouviu e conversou com Ele (6.813). Tal experiência ocorre de forma similar na vocação de Jeremias, onde Yahweh toca a boca do profeta (Jr 1.4-10). ${ }^{244}$

O que há em comum entre Zoroastro e Viraf em suas experiências visionárias é o estado alterado de consciência, ou êxtase, que não é tão evidente em Isaías e Jeremias. O êxtase prepara o visionário para receber a visão e desempenhou papel importante em experiências extáticas entre xamãs, profetas e outros tipos de autoridades religiosas (HULTGÅRD, 1982, p. 220). Em ZWY 3.6-8 Zoroastro é induzido ao êxtase por Ahura Mazda, que lhe dá de beber, em forma de água, a sabedoria de onisciência (xrad ì harwisp-āgāhīh ${ }^{245}$ ). Zoroastro pode ser descrito como um tipo de visionário extático (NYBERG, 1938, p. 146-187, HULTGÅRD, 1982, p. 222), na medida em que suas visões envolvem êxtase enquanto lhe é revelado conhecimento divino por Ahura Mazda.

O êxtase é um elemento em comum entre o profetismo, seja ele bíblico ou não bíblico, e a literatura apocalíptica ou apocalipsismo. Na Bíblia Hebraica há evidências de comportamento extático na literatura profética. O nābi, um dos termos utilizados na Bíblia Hebraica para designar o que profetiza, é associado ao transe profético nos casos de Saul (1 Sm 10.5-10) e no de Eliseu, onde a música ${ }^{246}$ é o meio pelo qual o profeta alcança o êxtase (2 Rs 3.15). É possível distinguir a natureza do êxtase dos profetas bíblicos, caracterizado na maioria das vezes pela calma, do êxtase de profetas pagãos, frequentemente orgíaco e vigoroso ${ }^{247}$ (ANDRÉ, 1982, p. 200). O êxtase de Zoroastro no

\footnotetext{
${ }^{244}$ Não se lida aqui com o fenômeno do êxtase propriamente dito, mas com narrativas sobre fenômenos extáticos.

${ }^{245} \mathrm{CPD}, \mathrm{xrad}\left[h / t^{\prime}\right]$, sabedoria; $\bar{\imath}[Y]$, de; harwisp [h/wsp'], todo; āgāhīh ['k's'], conhecimento.

${ }^{246}$ No Arda Viraf Namag sacerdotes e as sete irmãs recitam encantos religiosos do Avesta e cantam o Gathas na preparação do estado de êxtase de Viraf (AVN 2.17-19).

${ }^{247}$ A distinção é feita com base nas narrativas dos fenômenos de êxtase. Como não é possível ter acesso às experiências descritas, conjecturas sobre como os profetas vivenciavam o êxtase permanecem especulativas.
} 
NEARCD: Revista Eletrônica de Antiguidade 2020, Volume XII, Número II - ISSN IS82-8713

Núcleo de Estudas da Antiguidade - NEA

Universidade do Estado do Rio de Janeiro

ISSN 1982-8713

ZWY é marcado pela calma paralisante, pois ele dorme sete dias na sabedoria de Ahura Mazda. ${ }^{248}$

Partindo de um aspecto individual, como o êxtase, para um aspecto coletivo, pode-se considerar o profetismo iraniano um tipo de profetismo universal, já que no núcleo de suas ideias religiosas está o enfrentamento entre o bem e o mal cósmico e a espera de um salvador para uma salvação absoluta (NEHER, 1975, p. 34-35). Para entender como essas ideias aparecem no ZWY, é essencial compreender como a escatologia está disposta na obra, escatologia essa que se relaciona com o profetismo e a apocalíptica. ${ }^{249}$

\section{Escatologia e os sinais dos tempos}

Em suas visões, Zoroastro vê o tronco de uma árvore com quatro e depois sete galhos de materiais variados ${ }^{250}$ (ZWY 1.3, 3.19). A interpretação da visão é dada por Ahura Mazda, explicando a Zoroastro que os galhos representam quatro épocas, que correspondem a quatro governos vindouros. O galho/época de ouro é onde acontece a conversa entre Zoroastro e Ahura Mazda, o rei Wištāsp (Hystaspes) se converte à religião e afasta os demônios (dēws), (ZWY 1.8); o de prata é o reino de Ardaxšir, o rei Kayanida; o galho de aço é o reino de Husraw e o quarto galho, uma mistura de ferro e

\footnotetext{
248 /11/ No sétimo dia e noite, ele [Ahura Mazda] tomou de volta a sabedoria de onisciência de Zoroastro. /12/ Zoroastro considerou: "O que tenho visto no sonho agradável criado por Ahura Mazda? Ainda não estou acordado do sono". /13/ Ele levantou ambas as mãos, esfregou o próprio corpo e pensou: "Tenho dormido por muito tempo e ainda não estou acordado do sonho agradável criado por Ahura Mazda" (ZWY 3.11-13). Tradução minha com base na transcrição e tradução de CERETI, 1995.

${ }^{249} \mathrm{O}$ conceito de apocalíptica é mais amplo que o de escatologia e é importante distingui-los. Escatologia é a "doutrina das últimas coisas" ( $\tau \alpha$ $\varepsilon \sigma \chi \alpha \tau \alpha$ ), são as concepções sobre as últimas coisas que vêm após a morte, tanto para o indivíduo como para a humanidade. Apocalíptica, do grego óroкó $u \psi \psi \iota \varsigma$ (revelação), é uma manifestação, revelação acerca do curso da história do mundo, de sua criação ou de seu fim. (WIDENGREN, 1976, p. 405). A apocalíptica constitui ainda um gênero literário, de obras abundantes na antiguidade, modernamente categorizadas como apocalipses.

${ }^{250}$ As diferenças nas visões podem ser explicadas pelo uso de duas fontes diferentes na composição (HULTGÅRD, 1991, p. 127).
} 
outro elemento não especificado, acontecerá no fim do décimo século de Zoroastro, com o governo mau dos dēws de cabelo partido da raça de Xešm (ZWY 1.9-11).

Ahura Mazda explica ainda a variação da visão em outro sonho de Zoroastro, que na busca por imortalidade por uma segunda vez, vê uma árvore com sete galhos. A interpretação por Ahura Mazda segue a mesma lógica das idades e governos que virão da primeira visão: ouro (Wištāsp), prata (Ardaxšir), cobre (Ardaxšir, Sābuhr ll e Adurbād), bronze (Arsácidas), chumbo (Wahrām Gōr), aço (Husraw) e ferro misturado (raça de Xēšm), (ZWY 3.23-29).

Além da periodização da história em quatro e sete idades representadas por governos e metais, essa narrativa apresenta a ideia da degradação das épocas e materiais. Tal narrativa não é estranha a pelo menos mais uma fonte da literatura em persa médio, a Dēnkard. No quinto livro da Dēnkard há referência sobre eventos que acontecem em idades sucessivas, os tempos confusos de uma idade de aço e de ferro e ao rei Wištāsp (Dk 5.3), que no ZWY aparece sempre associado à idade de ouro (ZWY $1.8,3.23)$.

Um interessante paralelo às narrativas do ZWY e da Dk pode ser encontrado na literatura apocalíptica judaica e na literatura clássica, especificamente em Daniel e Hesíodo (DOBRORUKA, 2012). No capítulo 2 do livro canônico de Daniel, a visão da estátua segue ideias bastante similares, quatro reinos são associados a cada uma das partes da estátua de materiais variados: Nabucodonosor (cabeça de ouro); Média (peito e braços de prata); Pérsia (ventre e coxas de bronze) e o reino de Alexandre e seus herdeiros (pernas de ferro e pés parte de ferro e parte de argila), (Dn 2.31-45). Em Os Trabalhos e os Dias, Hesíodo descreve o mito das cinco raças humanas: uma raça de ouro; outra raça de prata; bronze; a raça dos heróis (semideuses) e a raça de ferro (Trabalhos 110-200).

Os temas em comum entre os capítulos 1 e 3 do ZWY, a Dk, Daniel e os Trabalhos é a periodização da história em idades de acordo com metais e a ideia da decadência de 
uma idade de ouro a uma idade de ferro. Aqui interessa principalmente os acontecimentos e sinais relacionados à idade de ferro misturado (ZWY 1.11, 3.29), o último dos períodos, que marca o fim do décimo século de Zoroastro, quando centenas e milhares de dēws ${ }^{251}$ de cabelo partido da raça de Xešm invadirão a terra do Irã (Éranšāhr), (ZWY 4.1-2). Algumas condições sociais, políticas e sinais cósmicos do fim do milênio de Zoroastro são: (1) Destruição de status da aristocracia, da verdade da religião, tratados, do santuário e da paz (ZWY 4.7, 33-36). (2) Desurbanização com a diminuição das províncias, cidades e vilas (ZWY 4.8). (3) Devastação das terras do Irã (ZWY 4.9). (4) Todos os homens serão enganadores e desejarão o mal uns aos outros, os grandes vínculos serão destruídos (ZWY 4.13 e 15). (5) A honra, o amor e a piedade desaparecerão do mundo (ZWY 4.14). (6) O sol ficará menor, os dias, meses e anos se encurtarão (ZWY 4.16). (7) vegetais, plantas e árvores diminuirão (ZWY 4.19). (8) Os homens nascerão menores, terão pouca habilidade e força; não terão gratidão e respeito pela hospitalidade, bem como amor pela família (ZWY 4.20). (9) Um pássaro terá mais respeito do que o iraniano e o homem piedoso (ZWY 4.21). (10) Contaminação do solo e de outros elementos sagrados, como o fogo e a água, com matéria morta (ZWY 4.23-30).

A noção de tan i pasēn, ${ }^{252}$ que na literatura pahlavi serve para designar um corpo escatológico, futuro ou final, é a expressão que mais corresponde etimologicamente à ideia de escatologia na tradição zoroástrica (TIMUŞ, 2004, p. 780). Como o conceito de escatologia é tomado emprestado da teologia judaico-cristã, é preciso aproximá-lo por analogia ao contexto persa. No ZWY o termo aparece pela primeira vez diante da negativa de Ahura Mazda em tornar Zoroastro imortal, pois isso impediria a realização

\footnotetext{
${ }^{251}$ Os dēws de cabelo partido da raça de Xešm são descritos levantando bandeiras, vestindo armaduras negras, com cabelos partidos para trás e urinando veneno (ZWY 4.4).

${ }^{252}$ CPD, tan [tn'], corpo; $\bar{\imath}[Y]$, de; pasēn [psyn'], final.
} 
NEARCD: Revista Eletrônica de Antiguidade 2020, Volume XII, Número II - ISSN IS82-8713

Núcleo de Estudas da Antiguidade - NEA

Universidade do Estado do Rio de Janeiro

ISSN 1982-8713

da ressurreição dos mortos ${ }^{253}$ e o corpo final (tan ì pasēn), (ZWY 3.3). No capítulo quatro, depois da revelação dos sinais que marcariam o fim do milênio de Zoroastro, a esperança no corpo final é destacada como uma crença que devia ser ensinada quando chegasse esse tempo (ZWY 4.67).

A escatologia pode ser individual, concentrando-se no fim do indivíduo, ou coletiva, quando se refere a fenômenos que envolvem o destino de todo um grupo ou da humanidade. Na tradição zoroástrica há dois julgamentos, um individual, da alma, imediatamente após a morte e outro universal, no fim dos tempos, após a ressurreição do corpo (HINTZE, 2019, p. 46).

A literatura em persa médio contém exemplos de escatologia coletiva e individual. Como exposto, o ZWY faz uma periodização da história do Irã e em alguns momentos em relação a outros povos; as ideias de ressurreição (rist-āxēz ${ }^{254}$ ) e renovação (frašgird ${ }^{255}$ ) reforçam a noção de coletivismo. Já no Arda Viraf Namag temos o melhor exemplo de escatologia pessoal, devido às extensas descrições sobre o destino dos mortos no submundo, sem a presença de escatologia política ou cósmica (COLLINS, 1979, p. 213).

A escatologia coletiva presente no ZWY o aproxima da ideia de um profetismo universal. Zoroastro recebe a revelação do que acontecerá nas idades e reinos sucessivos e é comissionado a ensinar, a partir de suas experiências visionárias, a vitória do bem sobre o mal, a ressurreição dos mortos, a espera por um corpo final bem como a renovação do mundo.

\footnotetext{
253 O problema da morte deve ser compreendido considerando a cosmovisão zoroástrica. No zoroastrismo, Ahura Mazda foi o criador do mundo espiritual e material, ambos perfeitos, sem deterioração e morte. $O$ mal não provém de Ahura Mazda, mas de uma fonte que lhe faz antagonismo e tenta corromper sua criação, Angra Mainyu (Ahriman). No fim dos tempos a morte deixará de existir, pois o mundo material voltará a seu estado de perfeição (HINTZE, 2019, p. 28-38).

${ }^{254} \mathrm{CPD}$, rist-āxēz [lyst'hyc], ressurreição dos mortos.

255 CPD, frašgird [plškrt'], a renovação (no fim dos tempos).
} 
ISSN 1982-8713

\section{Ressurreição e renovação}

A crença e espera pelo tan ì pasēn (corpo final) relaciona-se de maneira muito próxima com duas outras noções escatológicas: a de rist-āxēz (ressurreição) e a de frašgird (renovação), (TIMUŞ, 2004, p. 788). A periodização presente no ZWY é tradicional no zoroastrismo: o mundo é dividido em quatro períodos, durando três mil anos cada, mas o ZWY se concentra apenas no último período, que termina com a vinda do Saošyant, o último salvador, e a renovação cósmica (frašgird), (HULTGÅRD, 1991, p. 131).

Os capítulos 5, 6 e 7 do ZWY seguem o esquema de perguntas e respostas da literatura ham-pursagīh. No capítulo 7 Zoroastro pergunta a Ahura Mazda como seria possível a destruição dos dēws da raça de Xešm (7.1), que são muitos e personificados pelos exércitos dos povos inimigos do Irã. No capítulo 4 alguns desses povos são identificados como sendo os hunos, turcos, tibetanos, chineses, sogdianos, árabes e romanos, estes últimos representando os inimigos ocidentais dos persas (ZWY 4.58-59, 9.10).

Ao longo do capítulo 7 Ahura Mazda revela que serão enviadas figuras salvadoras para destruir os inimigos dos persas. Cada um dos mil anos decorrentes do último período da história zoroástrica testemunharia a ação de um salvador que nasceria de uma virgem por causa do banho no lago Kasaoiia, onde ficou preservado o sêmen de Zoroastro (Yt 19.92-93, MOAMAZI, 2000, p. 3).

As principais figuras salvadoras são Ušēdar, Ušēdarmāh e Sōšāns (persa médio). Em seu milênio, Ušédar seria ajudado por Pišotan e Kay Wahram, heróis iranianos cuja principal função é restaurar a religião e a soberania (ZWY 7.7 e 20), libertando o Irã dos dēws da raça de Xešm e dos exércitos inimigos com auxílio de outros guerreiros e heróis (ZWY 8.1-8). No milênio de Ušēdarmāh a criação seria mais ativa e poderosa, o salvador exterminaria os demônios da raça de $\bar{A} z$ e os homens seriam tão habilidosos na medicina e no uso de remédios que não morreriam exceto no tempo determinado ou por golpes 
NEARCD: Revista Eletrônica de Antiguidade 2020, Volume XII, Número II - ISSN IS82-8713

Núcleo de Estudas da Antiguidade - NEA

Universidade do Estado do Rio de Janeiro

ISSN 1982-8713

de espada ou faca (ZWY 9.11-12). A habilidade dos homens nesse milênio é análoga à multiplicação do conhecimento prevista para os últimos dias pelo livro de Daniel (Dn 12.4).

Os milênios de Ušēdar e Ušēdarmāh são um prelúdio da frašgird, fenômeno que é realizado pelo último dos filhos póstumos de Zoroastro, Sōšāns, que é o principal personagem da escatologia e apocalíptica iraniana (MOAMAZI, 2000, p. 10). O ZWY dedica pouco de sua narrativa ao milênio de Sōšāns, no entanto, é bastante expressivo sobre sua função: e o Sōšāns tornará a criação pura de novo, e a Ressurreição e o Corpo Final acontecerão ${ }^{256}$ (9.24). De acordo com Boyce, a crença num salvador persa do mundo (Saošyant), filho de Zoroastro que nasceria miraculosamente de uma virgem no fim dos tempos, estava estabelecida já em 1.200 a.C. (1984, p. 75). O Saošyant é o agente que possibilita a ressurreição dos mortos e restauração do mundo no Yt 19.8994 e no ZWY 9.24 .

O Yašt 19257, ou Zamyād Yašt, em seus versículos (stanzas) 89 a 94 relatam a ação futura do Saošyant como aquele que virá com seus ajudantes para "restaurar o mundo (frasho-kereti), o qual a partir de então nunca envelhecerá e nunca morrerá, (...) e pela sua vontade, quando os mortos ressuscitarem, quando a vida e imortalidade chegarem, o mundo será restaurado segundo seu desejo". Existe evidência de que o Yašt 19 forneceu um pano de fundo avéstico com a ideia de renovação do mundo e ressurreição por um último salvador tanto para o ZWY como para outros livros da literatura pahlavi (HULTGÅRD, 1998, p. 67). O Saošyant lembra o “Filho do Homem" (ben' adam) de Dn

\footnotetext{
${ }^{256}$ ud pas sōšāns dām abēzag abāz kunēd, ud ristāxēz ud tan ì pasēen be bawēd.

257 O Yt 19 não é do gênero apocalíptico, mas contém seções escatológicas. Apesar de pertencer à categoria geral de literatura zoroástrica ou persa, é preciso destacar que esse texto é parte da tradição avéstica, diferente do ZWY que é da literatura pahlavi. O termo yašt significa "oração", "adoração", e são hinos do Avesta dedicados a várias divindades do zoroastrismo. O Avesta, o texto mais sagrado do zoroastrismo, é uma compilação de obras que se dividem entre o Avesta gático (ou Avesta antigo, escrito em avéstico antigo) e o Avesta jovem (escrito no dialeto avéstico jovem), (BOYCE, 1990, p. 1).
} 
NEARCD: Revista Eletrônica de Antiguidade 2020, Volume XII, Número II - ISSN IS882-8713

Núcleo de Estudas da Antiguidade - NEA

Universidade do Estado do Rio de Janeiro

ISSN 1982-8713

7.13-14, mas embora faça parte de um contexto importante em Daniel, o Filho do Homem não aparece em relação explícita com a ressurreição dos mortos em Dn 12.1-3.

Além da tríade de ideias escatológicas, corpo final; ressurreição e renovação, o ZWY apresenta o tema da derrota de uma serpente ou dragão que representa os poderes destrutivos: Azdahāg é derrotado por Sāmān Keresāsp, trazendo o fim da desolação e infortúnio (ZWY 9.22-23). Referindo-se à literatura avéstica, Hintze explica que

No Yt 19.92-93, antes de ressuscitar os mortos, o perfeccionador iraniano, o vitorioso Saōshyant Astvatereta, mata o Engano, que representa o Mal, com a mesma arma com que mais cedo o herói Thraētaōna matou o dragão Dahāka. Essa vitória é seguida pela ressurreição dos mortos e o começo de uma nova era de felicidade eterna $(2019$, p. 58$) .258$

Apesar de não ser descrito em detalhes no ZWY, sabemos por outras fontes da literatura pahlavi que no milênio de Sōšāns haverá o último combate entre as forças do bem e do mal, e após a vitória sobre as forças de Ahriman, principal adversário de Ahura Mazda, os mortos serão ressuscitados e a criação será renovada (MOAMAZI, 2000, p. 11-14).

\section{Considerações finais}

No ZWY Zoroastro é representado muito mais como um profeta do que como um visionário apocalíptico. Ele tem contato direto com a divindade superior (Ahura Mazda) e é comissionado a propagar e ensinar o que lhe é revelado (4.67), num estilo

\footnotetext{
${ }^{258}$ Hintze propõe uma comparação com base em cinco elementos compartilhados entre zoroástricos (Yt 19), judeus (Isaías) e cristãos (Apocalipse de João) no mito escatológico: (1) chegada de um redentor (Yt 19.89-92, Astvatereta; Is 27.1, Yahweh; Ap 20.1, anjo); (2) ressurreição (Yt 19.89, 94; Is 26.19; Ap 20.4, 13); (3) julgamento (Yt 19.94; Is 26.20-21; Ap 20.4, 11-12, 15); (4) derrota do dragão, batalha (Yt 19.9293, 95-96; Is 27.1; Ap 20.2-3, 7-10, 14); (5) nova vida em felicidade (Yt 19.96; Is 27.2-6; Ap 21), (2019, p.5859). No ZWY podemos identificar a presença explícita de pelo menos quatro desses temas: chegada de redentores (ZWY 7.7 e 20); derrota da serpente ou dragão (ZWY 9.22-23); ressurreição e nova vida em felicidade (ZWY 9.24).
} 
parecido com as chamadas de profetas da Bíblia Hebraica. Como a abordagem comparativa entre a literatura apocalíptica judaica e persa é usual, é produtivo que se faça mais estudos comparativos entre a literatura profética judaica e seus possíveis paralelos na tradição zoroástrica.

Para uma melhor compreensão do ZWY, é preciso suspender o peso e aplicação de tipologias pré-estabelecidas do gênero apocalíptico. O êxtase e a escatologia são exemplos de elementos em comum entre o profetismo/literatura profética e o apocalipsismo/literatura apocalíptica. No entanto, o ZWY é estudado mais como um texto da literatura apocalíptica do que como um texto que também possui traços da literatura profética. No momento, a tipologia da literatura apocalíptica, estabelecida principalmente por meio dos esforços de estudiosos na Semeia 14 (COLLINS, 1979), carece de revisão e aperfeiçoamento e já existem estudos que trabalham nesse sentido. ${ }^{259}$ É um momento propício para estudos mais acurados dos elementos de literatura profética e apocalíptica nos textos da literatura pahlavi.

A estrutura literária do ZWY é moldada pelo mito das idades do mundo, que aparece numa versão de quatro e outra de sete idades. A narrativa destaca os sinais da última idade, que é a idade de ferro misturado, marcada pela ação maligna dos dēws de cabelo partido da raça de Xešm. O mito das idades do mundo presente no ZWY reforça as ideias escatológicas por sua teleologia, que vai do estabelecimento da religião pelos encontros entre Zoroastro e Ahura Mazda, da conversão do rei mítico Wištāsp até os eventos do fim dos tempos, de provações e redenção.

O ZWY possui uma importante tríade de ideias escatológicas: o tan i pasēn (corpo final); a rist-āxēz (ressurreição) e a frašgird (renovação). Essas ideias são parte de uma escatologia coletiva, que aproxima o texto à noção de profetismo universal. Ao mesmo

\footnotetext{
259 Destacam-se os livros The Architecture of Apocalypticism (From Antiquity to Armageddon) e ReImagining Apocalypticism: Apocalypses, Apocalyptic Literature and the Dead Sea Scrolls, ambos do Professor Lorenzo DiTommaso e que aguardam publicação.
} 
ISSN 1982-8713

tempo, essa tríade se insere perfeitamente num cenário de culminação escatológica que se espera de um texto de literatura apocalíptica. Essas características revelam um texto altamente compósito, que demanda atenção do leitor e dos estudiosos para as possibilidades da obra.

\section{Referências}

\section{Documentação}

BÍBLIA Hebraica Stuttgartensia. ELLIGER, Karl; RUDOLPH, Wilhelm (eds.); SCHENKER, Adrian (org.). Quinta edição revisada. Stuttgart: Deutsche Bibelgesellschaft, 1997.

CERETI, Carlo G. The Zand-i Wahman Yasn: A Zoroastrian Apocalypse. Roma: Istituto Italiano per II Medio ed Estremo Oriente, 1995.

HESÍODO. The Homeric Hymns and Homerica with an English Translation by Hugh G. Evelyn-White. Works and Days. Cambridge, MA: Harvard University Press; London: William Heinemann Ltd., 1914.

HINTZE, Almut. Zamyād Yašt. Introduction, Avestan text, translation, glossary. Wiesbaden: Reichert, 1994.

KASSOCK, Zeke. The Book of Arda Viraf. A Pahlavi Student's 2012 Rendition, Transcription and Translation. Fredericksburg: Kassock Bros. Publishing Co., 2012.

SANJANA, Pešotan. Sacred Books of the East VII. Bombay, 1894. Disponível em: <http://www.avesta.org/denkard/dk5s.html>. Acesso em: 30 ago. 2019.

\section{Bibliografia}

ANDRÉ, G. Ecstatic Prophecy in the Old Testament. In: Scripta Instituti Donneriani Aboensis, v. 11, 1982.

BOYCE, Mary. Middle Persian Literature. In: Handbuch der Orientalistik, vol. 4/1. Leiden: Brill, 1968. 
BOYCE, Mary. On the Antiquity of Zoroastrian Apocalyptic. In: Bulletin of School of Oriental and African Studies, 47, p. 57-75, 1984.

BOYCE, Mary. Textual sources for the study of Zoroastrianism. Chicago: The University of Chicago Press, 1990.

COLLINS, John J. Apocalypse: The Morphology of a Genre. In: Semeia, n. 14, 1979.

COLLINS, John J. The Apocalyptic Imagination: An Introduction to Jewish Apocalyptic Literature. Eerdmans/Grand Rapids, 1998.

COHN, Norman. Cosmos, Chaos, and the World to come: The Ancient Roots of Apocalyptic Faith. New Haven: Yale University Press, 1993.

DELITZSCH, F. Daniel. In: Realencyklopädie für protestantische Theologie und Kirche, III, 1855.

DOBRORUKA, Vicente. Hesiodic reminiscences in Zoroastrian-Hellenistic apocalypses. In: Bulletin of the School of Oriental and African Studies 75, p. 275-295, 2012.

DUCHESNE-GUILLEMIN, Jacques. Apocalypse juive et apocalypse iranienne. In: BIANCHI, Ugo e VERMASEREN, Maarten J. (eds.). La soteriologia dei culti orientali nell'Impero romano: atti del Colloquio internazionale su la soteriologia dei culti orientali nell'Impero romano. Leiden: Brill, 1982.

EDDY, Samuel K. The King is Dead: Studies in Near Eastern Resistence to Hellenism 33431 B.C. Lincoln: University of Nebraska Press, 1961.

GIGNOUX, Philippe. Les voyages chamaniques dans le monde iranien. In: Acta Iranica 21, 1981.

GIGNOUX, Philippe. L'apocalyptique iranienne est-elle vraiment la source d'autres Apocalypses? Acta Antiqua Academicae Scientiarum Hungaricae, n.31, p. 67-78, 1988.

GIGNOUX, Philippe. Sur l'inexistence d'un Bahman Yasht avestique. Journal of Asian and African Studies, n.32, p. 87-97, 1986.

HINTZE, Almut. On the Prophetic and Priestly Authority of Zarathustra. In: CHOKSY, J; DUBEANSKY, J. (eds.), Gifts to a Magus: Indo-Iranian Studies Honoring Firoze Kotwal. New York: Peter Lang, p. 43-58, 2012. 
HINTZE, Almut. Defeating Death: Eschatology in Zoroastrianism, Judaism and Christianity. In: Irano-Judaica VII. Studies Relating to Jewish Contacts with Persia. Jerusalem: The Ben-Zvi Institute for the Study of Jewish Communities in the East, p. 2372, 2019.

HULTGÅRD, Anders. Ecstasy and vision. In: HOLMS, Nils (ed.). Religious Ecstasy. Stockholm: Almqvist \& Wikseli International, p. 218-225, 1982.

HULTGÅRD, Anders. Forms and Origins of Iranian Apocalypticism. In: HELLHOLM, D. Apocalypticism in the Mediterranean World and the Near East, p. 387-411, 1983.

HULTGÅRD, Anders. Bahman Yasht: A Persian Apocalypse. In: COLLINS, John J; CHARLESWORTH, James H (eds.). Mysteries and Revelations: Apocalyptic Studies since the Uppsala Colloquium. Sheffield: Sheffield Academic Press, p. 114-134, 1991.

HULTGÅRD, Anders. Persian Apocalypticism. In: COLLINS, John J. (ed.). The Encyclopedia of Apocalypticism. The Origins of Apocalypticism in Judaism and Christianity. Vol. 1. New York: Continuum, 1998.

HUTTER, Manfred. Zoroaster iii: Zoroaster in the Avesta. In: Encyclopædia Iranica, disponível em: <http://www.iranicaonline.org/articles/zoroaster-iii-zoroaster-in-theavesta>, 2009. Acesso em: 29 ago. 2019.

KIPPENBERG, Hans G. Die Geschichte der mittelpersischen apokalyptischen Traditionen. Studia Iranica 7, p. 49-80, 1978.

MACKENZIE, D.N. A Concise Pahlavi Dictionary. Oxford: Oxford University Press, 1971.

MOAMAZI, Mahnaz. Millennialism, Escathology and Messianic figures in Iranian Traditions. Journal of Millennial Studies, p. 1-16, 2000.

NEHER, André. La esencia del profetismo. Salamanca: Ediciones Sígueme, 1975.

NYBERG, Henrik S. Die Religionen des alten Iran, Leipzig, 1938.

SWEENEY, Marvin A. Isaiah 1-39: with an Introduction to Prophetic Literature. Eerdmans/Grand Rapids, 1996.

TIMUŞ, Mihaela. Le "corps eschatologique" (tan ì pasēn) d'après la théologie zoroastrienne. In: Studia Asiatica IV. Université de Bucarest, Centre d'histoire des religions, 2004. 
NEARCD: Revista Eletrônica de Antiguidade 2020, Volume XII, Número II - ISSN IS82-8713

Núcleo de Estudas da Antiguidade - NEA

Universidade do Estado do Rio de Janeiro

ISSN 1982-8713

WIDENGREN, Geo. Fenomenología de la Religión. Madrid: Cristiandad, 1976.

WIDENGREN, Geo. Les quatre ages du monde. In: WIDENGREN, Geo et al. Apocalyptique iranienne et dualisme qoumrânien. Paris: Adrien Maisonneuve, 1995. 